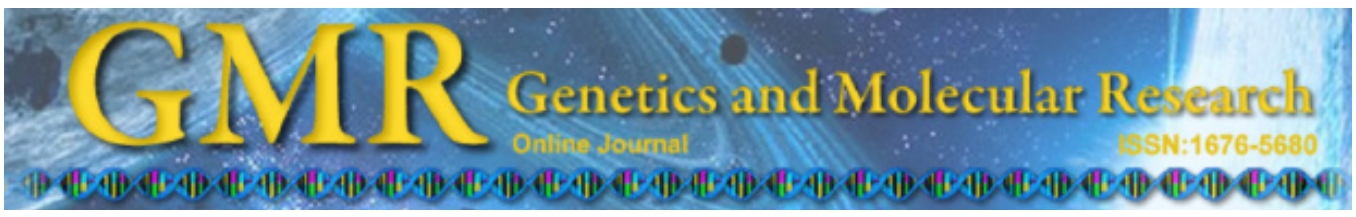

Letter to the Editor

\title{
Reply to commentary by Dr. Jürgen Reichling and associates on the article \\ "Genotoxicity and mutagenicity of Rosmarinus officinalis (Labiatae) essential \\ oil in mammalian cells in vivo", published in Genetics and Molecular Research
}

(2010); 9(4): 2114-2122.

\author{
E.L. Maistro \\ Corresponding author: E.L. Maistro \\ E-mail: edson.maistro@marilia.unesp.br \\ Genet. Mol. Res. 10 (2): 1095-1097 (2011) \\ Received May 11, 2011 \\ Published June 14, 2011 \\ DOI 10.4238/vol10-2gmr1481
}

Departamento de Fonoaudiologia, Faculdade de Filosofia e Ciências, Universidade Estadual Paulista Julio de Mesquita Filho, Marília, SP, Brasil

Dear Dr. Duarte,

From a genetic point of view, the data obtained with the routinely conducted micronucleus, comet and chromosome aberration assays and their interpretation are correct. However, upon checking the manuscript, we detected that two critical concerns pointed out by Dr. Reichling and associates are valid. Comparing the first version of the article sent for publication in GMR and the last, after the review process and language corrections, the conclusion sentence was published incompletely and the words "of it and" added in the Introduction section about the work of Lemonica et al. (1996) made the sentence incorrect.

The comments about the four critical questions are presented below:

1. "Chemical composition of Rosmarinus officinalis essential oil is well established in several phytochemical studies. The oil has demonstrated the presence of $\alpha$-pinene, camphene, $\beta$-pinene, sabinene, myrcene, $\alpha$-phelandrene, limonene, 1,8 -cineole, $\gamma$-terpinene, paracymene, $\alpha$-terpinolene, chrysanthenone, camphor, linalool, bornyl acetate, $\beta$-caryophyllene, 
terpinen-4-ol, verbenone, borneol, and geraniol (Tuberoso et al., 1998; Diab et al., 2002; Flamini et al., 2002; Angioni et al., 2004; Katerinopoulos et al., 2005; Atti-Santos et al., 2005). Despite the fact that some variations in the chemical composition of rosemary oil have been reported in relation to geographic origin, the analysis showed that the major constituents of the oil are the same, those being $\alpha$-pinene, 1,8-cineole, camphene, verbenone, borneol, camphor, and bornyl-acetate (Tuberoso et al., 1998; Diab et al., 2002; Angioni et al., 2004; Atti-Santos et al., 2005)". The above statement was in the first version of the article but was later removed as suggested by a referee. The phytochemical analysis of rosemary oil investigated in the manuscript was not made. Despite this, the data regarding the major constituents of the oil available in the literature were sufficient to justify its genotoxic assessment in our study.

2. The harmful side effects reported by Lemonica et al. (1996) were based on the analysis of an aqueous extract of rosemary leaves only. The words "of it and" were published incorrectly in the phrase, indicating (wrongly) that rosemary oil has the same effects. It is scientifically reasonable to think that if some extracts of aerial parts of rosemary showed some harmful side effects, other parts and extracts of this plant deserve to be investigated, especially from a mutagenicity viewpoint.

The other reports on rosemary extracts and oils with positive pharmacological effects were presented in the first six lines in the Introduction. The antioxidant activity reported exemplifies their antimutagenic potential.

3. The rosemary oil investigated in our paper was obtained from leaves, although we used the words "aerial parts" in the Material and Methods section (and it should be noted that the leaves constitute the great proportion of this part of this plant). The oil doses tested were 300,1000 and $2000 \mathrm{mg} / \mathrm{kg}$ b.w. and not $3000 \mathrm{mg} / \mathrm{kg}$ b.w. as indicated in the letter to the Editor. The doses were selected on the basis of acute toxicity studies in mice and the effective dose $\left(\mathrm{ED}_{50}\right)$ determined in anti-inflammatory and analgesic activity analysis using the oil (Faria, 2005). Regulatory guidelines recommend that the high dose selected for the rodent genotoxic assays should produce some toxicity, which was the maximum tolerated dose (MTD), or 2000 $\mathrm{mg} / \mathrm{kg}$. Generally, the MTD is the highest dose that can be administered without inducing lethality or excessive toxicity during the study. It has also been recommended that the intermediate dose be one-half of the high dose and the low dose be one-half of the intermediate dose (Krishna and Hayashi, 2000). We used the $300 \mathrm{mg} / \mathrm{kg}$ dose to verify if $\mathrm{ED}_{50}$ determined by Faria (2005) had genotoxic potential.

4. We agree that the conclusion published in the manuscript is inadequate. This occurred because during language correction/editing, one important part was deleted and this was not seen in our last revision. The complete conclusion phrase is:

"Based on our experimental conditions, we conclude that high doses of rosemary oil induce genotoxicity in peripheral blood and liver cells of mice, and that doses above the $\mathrm{ED}_{50}$ induce mutagenicity in bone marrow cells of rats and mice without affecting cell division".

We thank Dr. Reichling and associates very much for the critical questions they posed, because we now had the opportunity to correct some shortcomings that went undetected in our last revision of the manuscript before its publication in GMR.

Sincerely, Prof. Dr. Edson Luis Maistro and co-authors. 


\section{REFERENCES}

Angioni A, Barra A, Cereti E, Barile D, et al. (2004). Chemical composition, plant genetic differences, antimicrobial and antifungal activity investigation of the essential oil of Rosmarinus officinalis L. J Agric. Food Chem. 52: 3530-3535.

Atti-Santos AC, Rossato M, Pauletti GF, Rota LD, et al. (2005). Physico-chemical evaluation of Rosmarinus officinalis L. essential oils. Braz. Arch. Biol. Technol. 48: 1035-1039.

Diab Y, Auezova L, Chebib H, Chalchat JC, et al. (2002). Chemical composition of Lebanese rosemary (Rosmarinus officinalis L.) essential oil as a function of the geographical region and the harvest time. J. Essent. Oil Res. 14: 449452.

Faria LRD (2005). Pharmacological Validation of the Essential Oil from Rosmarinus Officinalis L. (Rosemary) - AntiInflammatory and Analgesic Activities. Master's thesis, UNIFENAS, Alfenas.

Flamini G, Cioni PL, Morelli I, Macchia M, et al. (2002). Main agronomic-productive characteristics of two ecotypes of Rosmarinus officinalis L. and chemical composition of their essential oils. J. Agric. Food Chem. 50: 3512-3517.

Katerinopoulos HE, Pagona G, Afratis A, Stratigakis N, et al. (2005). Composition and insect attracting activity of the essential oil of Rosmarinus officinalis. J. Chem. Ecol. 31: 111-122.

Krishna G and Hayashi M (2000). In vivo rodent micronucleus assay: protocol, conduct and data interpretation. Mutat. Res. 455: 155-166.

Lemonica IP, Damasceno DC and di-Stasi LC (1996). Study of the embryotoxic effects of an extract of rosemary (Rosmarinus officinalis L.). Braz. J. Med. Biol. Res. 29: 223-227.

Tuberoso CIG, Satta M, Cabras P and Garau VL (1998). Chemical composition of Rosmarinus officinalis of Sardinia. J. Essent. Oil Res. 10: 660-664. 